\title{
Anti-A Production by a Group 0 Spleen Transplanted to a Group A Recipient
}

\author{
D.J. Salamon, G. Ramsey, J. Nusbacher, S. Yang, T.E. Starzl, L. Israel \\ Central Blood Bank and the Departments of Medicine, Pathology, and Surgery, University of Pittsburgh, \\ Pa., USA
}

\begin{abstract}
A group $A_{1}$ diabetic received a pancreas-spleen transplant from a group 0 donor. Severe immune hemolysis due to anti-A ensued, requiring graft splenectomy. The transplanted spleen can be a potent source of blood group antibody.
\end{abstract}

\section{Introduction}

The temporary appearance of anti-A or anti-B isohemagglutinins in non-group 0 patients receiving a transplanted organ from a group 0 donor has been observed following transplantation of lung [1], kidney [2-4], and liver [5]. We have investigated a case of antiA formation and severe hemolysis following pancreas-spleen transplantation from a group 0 donor into a group A recipient.

\section{Materials and Methods}

The patient's serum was tested for the presence of $\mathrm{AB} 0$ antibody activity at room temperature $(\mathrm{RT}), 37^{\circ} \mathrm{C}$, and by antiglobulin testing with freshly drawn $A_{1}, A_{2}, B$, and 0 red blood cells (RBC). The direct antiglobulin tests, $56^{\circ} \mathrm{C}$ heat eluates, and dithiothreitol (DTT) treatment of the serum were performed by established procedures [6]. Agglutination reactions were scored as described by Issitt and Issitt [7].

\section{Case History and Results}

The patient was a group $A_{1} 35$-year-old white male admitted for pancreas transplantation. He had been a diabetic requiring insulin injections since the age of 5 . In addition to neuropathy and retinopathy, in 1981 he developed renal failure and required dialysis. In December 1982 he received a successful cadaveric kidney transplant with cyclosporine immunosuppression. Despite a strict insulin regimen, his blood glucose ranged between 44 and $425 \mathrm{mg} / \mathrm{dl}$, without good control. On March 6, 1983, he received a cadaveric pancreas transplant from a group 0 donor. The donor pancreas, spleen, and a segment of duodenum were transplanted en bloc, with the duodenum anastomosed to the recipient's jejunum [8]. The recipient's pancreas and spleen were left in situ. The estimated blood loss during surgery was about $100 \mathrm{ml}$. No blood products were 


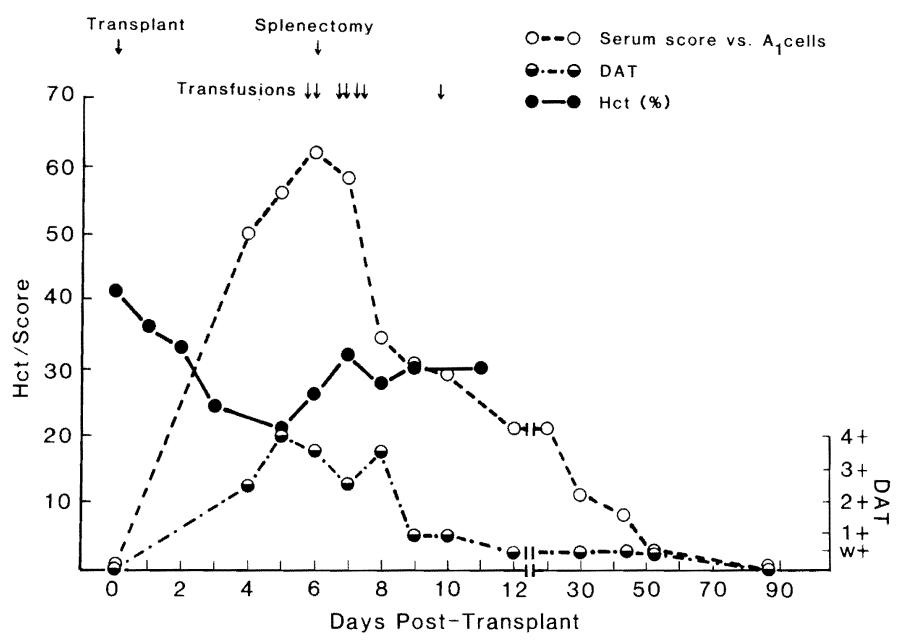

Fig. 1. Serologic and hematologic course after transplantation of group 0 spleen to group $\mathrm{A}_{1}$ recipient. transfused. A course of corticosteroids was added to the ongoing cyclosporine immunosuppression.

The patient's clinical course is illustrated in figure 1. The hemoglobin and hematocrit on the day of surgery were $13.8 \mathrm{~g} / \mathrm{dl}$ and $41.3 \%$, but fell steadily over the first 5 postoperative days to $7.4 \mathrm{~g} / \mathrm{dl}$ and $21 \%$, respectively, with no evidence of hemorrhage. At this time, the haptoglobin was $35 \mathrm{mg} / \mathrm{dl}$ and reticulocyte count $5.5 \%$. Direct and indirect serum bilirubin were 1.0 and $2.9 \mathrm{mg} / \mathrm{dl}$, respectively. The urine was positive for urobilinogen. The platelet count declined from a preoperative level of $232 \times 10^{9} / 1$ to $137 \times 10^{9} / 1$ by the 7 th postoperative day.

Prior to surgery, the direct and indirect antiglobulin tests were negative. Because of the falling hematocrit, blood was ordered crossmatched for transfusion 4 days after surgery. Group A units were found to be incompatible at RT $(1+), 37^{\circ} \mathrm{C}(1+)$ and by antiglobulin testing (3+). The direct antiglobulin test (DAT) was positive (broad spectrum 4+, anti-IgG 3+, anticomplement
1+). Antibody eluted from the patient's RBC agglutinated $\mathrm{A}_{1}$ cells $(4+)$ and $\mathrm{A}_{2}$ cells (1+), but not group 0 cells. From days $4-6$ postoperatively, serum anti-A agglutination scores against group $\mathrm{A}_{1}$ cells at $\mathrm{RT}, 37^{\circ} \mathrm{C}$, and at the antiglobulin phase, rose from 10 , 5 , and 50 to 10,10 , and 62 , respectively. DTT treatment of the patient's serum reduced the scores only slightly. No reactivity was observed when testing the patient's serum against $\mathrm{A}_{2}$ cells. After absorption of the serum with $A_{1}$ cells, an eluate from these cells reacted $1+$ with $A_{1}$ cells, very weakly with $\mathrm{A}_{2}$ and $\mathrm{B}$ cells, and was negative with group 0 cells. On day 6 , the transplanted spleen was removed. The spleen weighed $190 \mathrm{~g}$ (normal $150 \mathrm{~g}$ ); histopathology showed prominent immunoblastic proliferation and red pulp congestion, consistent with immune stimulation and hemolysis. During and after splenectomy the patient received a total of 7 units of washed group $0 \mathrm{RBC}$.

After splenectomy the anti-A scores fell steadily but the antibody was still detectable 7.5 weeks later. The patient's hematocrit 
stabilized and his blood glucose became normal. All evidence of anti-A disappeared by 3 months, and was also absent 1 year later.

\section{Discussion}

This group $A_{1}$ patient had severe immune hemolysis due to anti-A after transplantation of a group 0 spleen with a pancreatic graft. The antibody was of $A_{1}$ specificity, though a trace of anti- $\mathrm{AB}$ activity was detectable in the serum. While it is likely that plasma containing anti-A was administered passively along with the transplanted organs, the following evidence indicates that the transplanted spleen was actively producing anti-A isohemagglutinins: (1) The volume of plasma in the transplant was undoubtedly small and would be diluted substantially in the recipient's plasma. (2) Plasma anti-A levels rose significantly between postoperative days 4 and 6 , indicating synthesis of new antibody. (3) The DAT also increased in strength during this period of time. (4) Splenectomy of the graft reversed this process. (5) The spleen showed evidence of immune stimulation on histological examination. We conclude that the spleen, a large lymphoid organ, produced a marked graft-versus-host anti-A isohemagglutinin response when challenged by the transplant recipient's $A_{1}$ antigen.

Inclusion of the spleen in total pancreatic transplantation offers several possible advantages [8]. The splenic vessels supply much of the pancreatic venous drainage, and preserving them in toto may help prevent splenic vein thrombosis, a common problem in this procedure. Intraoperative trauma to the pancreas may be lessened by a wider en bloc dissection. Experimental evidence sug- gests a protective effect of splenic transplantation on survival of other concomitant organ grafts, including the pancreas [9]. However, as shown in our case, the donor should have the same $\mathrm{AB} 0$ group as the recipient, an important consideration in future transplants of this kind.

A case similar to ours was reported in 1964 [10]. In an experimental protocol attempting transfer of tumor immunity to patients with carcinoma, 1 group A recipient received a group 0 spleen. Severe hemolysis ensued. While being prepared for splenectomy, the patient aspirated and died. The pathogenesis of this hemolysis was undoubtedly the same as in our case.

Anti-recipient $\mathrm{AB} 0$ antibody has occasionally been reported after other instances where a group 0 organ was transplanted to a group A recipient. Beck et al. [1] noted a lung transplant patient in which a positive direct antiglobulin test occurred. 30 -to-A kidney transplants have been followed by mild to moderate hemolysis due to anti-A, the antibody persisting for up to 60 days after surgery [2-4]. We have studied 8 cases of moderate to severe hemolysis due to anti-recipient $\mathrm{AB} 0$ antibody after unmatched liver transplantation, including recipients who were group $\mathrm{B}$ and $\mathrm{AB}$ as well as group $\mathrm{A}$ [5]. In addition to the spleen, the largest lymphoid organ, these other grafts apparently also can contain enough lymphocytes to form clinically significant antibodies to host red cells, even in the setting of posttransplant immunosuppression.

\section{Acknowledgements}

We gratefully acknowledge the dedicated secretarial support of Linda Lippert. 


\section{References}

1 Beck, H.; Haines, R.; Oberman, H.: Unexpected serologic findings following lung homotransplantation (Abstract). Am. Ass. Blood Banks, 24th Annu. Meet., Chicago 1971.

2 Bird, G.; Wingham, J.: Anti-A autoantibodies with unusual properties in a patient on renal dialysis. Immunol. Commun. 9: 155-159 (1980).

3 Stevens, J.; Callender, C.; Jilly, P.: Emergence of red blood cell agglutinins following renal transplantation in a patient with systemic lupus erythematosus. Transplantation 32: 398-400 (1981).

4 Contreras, M.; Hazelhurst, G.; Armitage, S.: Development of 'auto-anti- $A_{1}$ antibodies' following alloimmunization in an $\mathrm{A}_{2}$ recipient. Br. J. Haemat. 55: 657-663 (1983).

5 Ramsey, G.; Nusbacher, J.; Starzl, T.; Lindsay, G.: Isohemagglutinins of graft origin after ABO-unmatched liver transplantation. New Engl. J. Med. (in press).

6 Widmann, F.: Technical manual of the American Association of Blood Banks (Lippincott, Philadelphia 1981).

7 Issitt, P.; Issitt, C.: Applied blood group serology (Spectra Biologicals, Oxnard 1975).

8 Starzl, T.; Iwatsuki, S.; Shaw, B.; Greene, D.; Van Thiel, D.; Nalesnik, M.; Nusbacher, J.; Diliz-Perez, H.; Hakala, T.: Pancreatico-duodenal transplantation in humans. Surgery Gynec. Obstet. 159: 265-272 (1984).

9 Bitter-Suermann, H.; Save-Soderbergh, J.: The course of pancreas allografts in rats conditioned by spleen allografts. Transplantation 26: $28-34$ (1978).
10 Marchioro, T.; Rowlands, D.; Rifkind, D.; Waddell, W.; Starzl, T.; Fudenberg, H.: Splenic homotransplantation. Ann. N.Y. Acad. Sci. 120:626-651 (1964).

\section{Addendum}

Since this manuscript was submitted, two additional reports have appeared of $\mathrm{AB} 0$ antibodies attributable to unmatched renal transplants $[1,2]$.

1 Mangal, A.; Growe, G.; Sinclair, M.; Stillwell, G.; Reeve, C.; Naiman, S.: Acquired hemolytic anemia due to 'auto'-anti-A or 'auto'-anti-B induced by group 0 homograft in renal transplant recipients. Transfusion, philad. 24: 201-205 (1984).

2 Nyberg, G.; Sandberg, L.; Rydberg, L.; Gabel, H.; Persson, H.; Wedel, N.; Ahlmen, J.; Brynger, H.: $\mathrm{AB} 0$-autoimmune hemolytic anemia in a renal transplant patient treated with cyclosporine. Transplantation 37: 530-531 (1984).

Received: April 26, 1984

Accepted: August 6, 1984

Prof. Jacob Nusbacher, Central Blood Bank, 812 Fifth Avenue, Pittsburgh, PA 15219 (USA) 